Pacific Journal of Mathematics

ON SYMMETRY IN CERTAIN GROUP ALGEBRAS 


\title{
ON SYMMETRY IN CERTAIN GROUP ALGEBRAS
}

\author{
DuANe W. BaIley
}

\begin{abstract}
A complex Banach algebra $A$ with involution $x \rightarrow x^{*}$ is symmetric if $\operatorname{Sp}\left(x^{*} x\right) \subset[0, \infty)$ for each $x \in A$. It is shown that (i) if $A$ is symmetric, the algebra of all $n \times n$ matrices with elements from $A$ is symmetric, and (ii) the group algebra of any semi-direct product of a finite group with a locally compact group having a symmetric group algebra is again symmetric.
\end{abstract}

An involution $x \rightarrow x^{*}$ in $A$ is said to be hermitian if Sp $(x) \subset(-\infty, \infty)$ for every self-adjoint $x \in A$. In [1] $\mathrm{R}$. Bonic studied the natural involution in the group algebra of certain discrete groups and raised the question: Is the group algebra of a semi-direct product of a finite group with a discrete Abelian group necessarily symmetric? The present work is devoted to proving the more general result that the group algebra of any semi-direct product of a finite group with a locally compact group whose group algebra is symmetric, is again symmetric. The proof in part depends upon showing that the algebra of $n \times n$ matrices with elements from a symmetric Banach algebra has a naturally defined symmetric involution. (We restrict our attention to continuous involutions.)

I am indebted to the referee for pointing out that if $G$ is discrete, our Theorem 2 follows from a result of A. Hulanicki (Corollary 2, page 286 of [4]). Also, while it is easy to show that every symmetric involution is necessarily hermitian and that the notions are equivalent for commutative algebras, the equivalence for noncommutative algebras was an open question until quite recently. Mr. S. Shirali has announced a positive solution to this question which will be contained in his Doctoral Dissertation at Harvard University.

1. Algebras of matrices. Let $A$ be a Banach algebra with a continuous involution $x \rightarrow x^{*}$. A linear functional $f$ on $A$ is positive if $f\left(x^{*} x\right) \geqq 0$ for all $x \in A$. If $A$ contains an identity $e$, such a functional satisfies $f\left(y^{*} x\right)=f\left(x^{*} y\right)$ for all $x, y \in A$, and if $A$ is symmetric, then

$$
\operatorname{Sp}(x) \subset\{f(x) \mid f \text { a positive functional, } f(e)=1\}
$$

whenever $x \in A$ and $x^{*} x=x x^{*}$. (For a proof of these and other facts about symmetric Banach algebras, see [5].) In the following, $\nu(x)$ denotes the spectral radius of $x$. 
LEMMA 1. Let $A$ be a Banach algebra with identity and continuous involution, and let $f$ be a positive linear functional on A. Then

( i ) $\left|f\left(x^{*} h x\right)\right| \leqq f\left(x^{*} x\right) \nu(h)$ whenever $x, h \in A$ and $h^{*}=h$.

( ii ) $\left|f\left(\sum_{i=1}^{n} y_{i}^{*} x_{i}\right)\right|^{2} \leqq f\left(\sum_{i=1}^{n} y_{i}^{*} y_{i}\right) f\left(\sum_{i=1}^{n} x_{i}^{*} x_{i}\right)$ whenever $x_{i}, y_{i} \in A$.

(iii ) $f\left(\left(\sum_{i=1}^{n} y_{i}^{*} x_{i}\right)^{*}\left(\sum_{i=1}^{n} y_{i}^{*} x_{i}\right)\right) \leqq f\left(\sum_{i=1}^{n} x_{i}^{*} x_{i}\right) \nu\left(\sum_{i=1}^{n} y_{i}^{*} y_{i}\right)$ whenever

$$
x_{i}, y_{i} \in A \text {. }
$$

Proof. For (i), see [5, Th. 4.5.2]. Part (ii) is a generalized Cauchy inequality and is easy to prove using the properties of $f$ mentioned above. If the left side of (iii) is 0 , there is nothing to prove. Otherwise, we use (i) and (ii) to write

$$
\begin{aligned}
(f( & \left.\left.\left(\sum_{i=1}^{n} y_{i}^{*} x_{i}\right)^{*}\left(\sum_{j=1}^{n} y_{j}^{*} x_{j}\right)\right)\right)^{2} \\
& =\left(f\left(\sum_{i=1}^{n} x_{i}^{*}\left(y_{i} \sum_{j=1}^{n} y_{j}^{*} x_{j}\right)\right)\right)^{2} \\
& \leqq f\left(\sum_{i=1}^{n} x_{i}^{*} x_{i}\right) f\left(\sum_{i=1}^{n}\left(\sum_{j=1}^{n} y_{j}^{*} x_{j}\right) y_{i}^{*} y_{i}\left(\sum_{j=1}^{n} y_{j}^{*} y_{j}\right)\right) \\
& \leqq f\left(\sum_{i=1}^{n} x_{i}^{*} x_{i}\right) f\left(\left(\sum_{j=1}^{n} y_{j}^{*} x_{j}\right)^{*}\left(\sum_{j=1}^{n} y_{j}^{*} x_{j}\right)\right) \nu\left(\sum_{i=1}^{n} y_{i}^{*} y_{i}\right) .
\end{aligned}
$$

We obtain (iii) by cancelling a common factor from both sides.

The set $A_{n}$ of all $n \times n$ matrices with elements from $A$ can be made into an algebra by defining the operations exactly as for matrices of scalars. Furthermore, if $X \in A_{n}, X=\left[x_{i j}\right]$, the mapping $X^{*}=\left[y_{i j}\right]$, where $y_{i j}=x_{j i}^{*}$, is easily seen to be an involution in $A_{n}$. (We use the same symbol for the involution in the two algebras since confusion seems unlikely.) Finally,

$$
\|X\|=\max _{i=1, \cdots, n} \sum_{j=1}^{n}\left\|x_{i j}\right\|, \quad X \in A_{n},
$$

is a Banach algebra norm for $A_{n}$.

THEOREM 1. If $A$ is symmetric then $A_{n}$ is symmetric for any positive integer $n$.

We note that it is sufficient to prove the theorem for the case in which $A$ has an identity $e$. For otherwise, let $A_{e}$ denote the algebra obtained by adjoining an identity to $A$. It is known [2 or 5] that $A_{e}$ is symmetric if and only if $A$ is symmetric. So, to show 
that $A_{n}$ is symmetric we simply observe that $\left(A_{n}\right)_{e}$ is *-isomorphic to a closed *-subalgebra of $\left(A_{e}\right)_{n}$. The isomorphism here is

$$
\left[x_{i j}\right]+\lambda E \leftrightarrow\left[x_{i j}+\lambda \delta_{i j} e\right] .
$$

Any closed *-subalgebra of a symmetric Banach algebra is again symmetric, so it is enough to know that $\left(A_{e}\right)_{n}$ is symmetric.

Lemma 2. The theorem is true for $n=2$.

Proof. Let $X \in A_{2}, X=\left[x_{i j}\right]$. Then $X^{*} X=\left[y_{i j}\right]$ where

$$
y_{i j}=x_{1 i}^{*} x_{1 j}+x_{2 i}^{*} x_{2 j}, \text { and } y_{i j}=y_{j i}^{*}, \quad i, j=1,2 \text {. }
$$

To prove that $A_{2}$ is symmetric, it is enough to show that $-1 \notin \operatorname{Sp}\left(X^{*} X\right)$. That is, if $E$ is the identity matrix in $A_{n}, E=\left[\delta_{i j} e\right]$, then $E+X^{*} X$ possesses an inverse. We will exhibit this inverse.

It is first necessary to establish the invertibility of two elements of $A$. As in [5], if $x \in A$ satisfies $\operatorname{Sp}(x) \subset[0, \infty)$ we write $x \geqq 0$. The symmetry of $A$ implies [5, Lemma 4.7.10]

$$
y_{11}=x_{11}^{*} x_{11}+x_{21}^{*} x_{21} \geqq 0 \text {. }
$$

Thus $e+y_{11}$ has an inverse, say $d_{1}$. Next we consider $y_{22}-y_{21} d_{1} y_{12}$. If $f$ is a positive linear functional on $A, f(e)=1$, then

$$
\begin{aligned}
f\left(y_{21} d_{1} y_{12}\right) & \leqq f\left(y_{21} y_{12}\right) \nu\left(d_{1}\right) \\
& \leqq f\left(y_{22}\right) \nu\left(y_{11}\right) \nu\left(d_{1}\right) \\
& \leqq f\left(y_{22}\right)
\end{aligned}
$$

from Lemma 1 (iii) and known properties of $\nu$. It then follows that $f\left(y_{22}-y_{21} d_{1} y_{12}\right) \leqq 0$ and, as a consequence of (1.1),

$$
y_{22}-y_{21} d_{1} y_{12} \geqq 0 \text {. }
$$

We now know that $e+y_{22}-y_{21} d_{1} y_{12}$ has an inverse, say $d_{2}$. It is then an easy matter to verify that the matrix

$$
\left[\begin{array}{cc}
d_{1}+d_{1} y_{12} d_{2} y_{21} d_{1} & -d_{1} y_{12} d_{2} \\
-d_{2} y_{21} d_{1} & d_{2}
\end{array}\right]
$$

is an inverse for $E+X^{*} X$. Hence $A_{2}$ is symmetric.

LEMmA 3. The theorem holds for $n=2^{k}$, where $k$ is any positive integer.

Proof. The proof is by induction, the case $k=1$ being covered by Lemma 2. If we assume the result for $k=m$, then it follows 
for $k=m+1$ from the fact that $A_{2 m+1}$ is *-isomorphic to $\left(A_{2 m}\right)_{2}$ by partitioning. In fact, every matrix in $A_{2 m+1}$ corresponds to a $2 \times 2$ matrix of matrices from $A_{2}$, and this correspondence is easily proved to be a ${ }^{*}$-isomorphism.

Proof of Theorem 1. If $n$ is a positive integer, choose $k$ a positive integer so large that $m=2^{k}>n$. Then $A_{m}$ is symmetric, by Lemma 3 , and the closed *-subalgebra of $A_{m}$ consisting of all matrices with 0 in the last $(m-n)$ rows and columns is obviously *-isomorphic to $A_{n}$. It follows that $A_{n}$ is itself symmetric, and the proof is complete.

2. Group algebras and semi-direct products. If $F$ is a locally compact group, let $I_{F}$ denote a left invariant Haar integral on $F$ and let $\Delta_{F}$ be the corresponding modular function. Thus $J_{F}(x)=I_{F}\left(x \cdot 1 / \Delta_{F}\right)$ is a right invariant Haar integral on $F$. The group algebra of $F$ is the Banach space $L^{1}(F)$ of all complex-valued functions on $F$ which are absolutely integrable with respect to the corresponding left Haar measure, $\mu_{F}$. This algebra has an involution defined by $x^{*}(f)=$ $x\left(f^{-1}\right) \Delta_{F}\left(f^{-1}\right), f \in F$. (Here again we use ${ }^{*}$, in different positions, to denote both convolution and the involution.)

Let $F$ and $G$ be locally compact groups, and let $f \rightarrow \phi_{f}$ be a homomorphism of $F$ into the group of automorphisms of $G$ such that $(f, g) \rightarrow \phi_{f}(g)$ is a continuous mapping of $F \times G$ into $G$. In particular, each $\phi_{f}$ is continuous (and hence a homeomorphism). Let $S=F \times G$ and define a multiplication in $S$ by

$$
\left(f_{1}, g_{1}\right)\left(f_{2}, g_{2}\right)=\left(f_{1} f_{2}, g_{1} \phi_{f_{1}}\left(g_{2}\right)\right), \quad\left(f_{i}, g_{i}\right) \in S, i=1,2 \text {. }
$$

Then $S$ becomes a locally compact group which we denote by $F \times_{\phi} G$. We note in passing that the inverse of $(f, g)$ is $\left(f^{-1}, \phi_{f-1}\left(g^{-1}\right)\right)$.

We now observe that the automorphisms $\phi_{f}$ induce a group of bounded linear transformations $\Phi_{f}$ of $L^{1}(G)$ defined by

$$
\Phi_{f}(x)=x \circ \phi_{f-1} \quad \text { for } f \in F, x \in L^{1}(G) \text {, }
$$

and the mapping $f \rightarrow \Phi_{f}$ is a homomorphism of $F$ onto this group. To see that the range of $\Phi_{f}$ is contained in $L^{1}(G)$, it is sufficient to note that each $\phi_{f}$ maps the measurable subsets of $G$ onto measurable subsets, and that for some $\delta(f)>0$

$$
\mu_{G}\left(\dot{\phi}_{f}(E)\right)=\delta(f) \mu_{G}(E)
$$

is satisfied by every measurable set $E \subset G$. Because $\phi_{f}$ is a homeomorphism, it maps Borel sets of $G$ onto Borel sets, and because it is also an automorphism, the measure 


$$
\mu_{G}^{f}(B)=\mu_{G}\left(\phi_{f}(B)\right), \quad B \text { a Borel set },
$$

is left-invariant. This measure clearly satisfies conditions (iv)-(vii) of [3, p. 194] and consequently, by the uniqueness of left Haar measure, (2.1) is satisfied for some $\delta(f)>0$ and all Borel sets. Furthermore, the outer measure

$$
\mu^{*}(E)=\inf \left\{\mu_{G}(A) \mid A \text { is open, } E \subset A\right\}
$$

induced by $\mu_{G}$ also satisfies

$$
\mu^{*}\left(\phi_{f}(E)\right)=\delta(f) \mu^{*}(E)
$$

for every subset $E \subset G$. It is then easy to verify (using [3, Th. 11.32] for example) that (2.1) holds for every measurable set $E$. In particular, if $G$ is compact, any topological automorphism of $G$ is measure preserving.

Clearly the mapping $\delta$ is a homomorphism of $F$ into the multiplicative group of positive real numbers and

$$
I_{G}\left(\Phi_{f}(x)\right)=I_{G}\left(x \circ \phi_{f-1}\right)=\delta(f) I_{G}(x), \quad x \in L^{1}(G) .
$$

In these terms, the modular function for $S$ can be expressed as

$$
\Delta_{S}(f, g)=\delta\left(f^{-1}\right) \Delta_{F}(f) \Delta_{G}(g) .
$$

The principal concern of this paper is the case in which $F$ is finite. In this case the functions $\Delta_{F}$ and $\delta$ are obviously identically 1 .

Theorem 2. Let $F$ be a finite group, and let $G$ be a locally compact group whose group algebra is symmetric. Then any semidirect product $S=F \times{ }_{\phi} G$ has a symmetric group algebra.

Proof. Let $x \in L^{1}(S), x=x(f, g)$. For each $f \in F$ the function $x_{f}(g)=x(f, g)$ is, by Fubini's theorem, in $L^{1}(G)$. Conversely, if $\mathrm{y}_{f} \in L^{1}(G)$ for each $f \in F$ and $y$ is defined by $y(f, g)=y_{f}(g)$, then $y \in L^{1}(S)$. In this manner $L^{1}(S)$ is identified with the space of all $L^{1}(G)$-valued functions defined on $F$. Now,

$$
x^{*}(f, g)=x\left(f^{-1}, \phi_{f-1}\left(g^{-1}\right)\right) \Delta_{G}\left(\phi_{f-1}\left(g^{-1}\right)\right)=\Phi_{f}\left(\left(x_{f-1}\right)^{*}\right)(g)
$$

and

$$
\begin{aligned}
x^{*} x(f, g) & =I_{S}\left(x^{*}[r, s] x\left[(r, s)^{-1}(f, g)\right]\right) \\
& \left.=I_{F}\left(I_{G}\left(\Phi_{r}\left(\left(x_{r-1}\right)^{*}\right)(s) \Phi_{r}\left(x_{r-1 f}\right) s^{-1} g\right)\right)\right) \\
& =\sum_{f \in F} \Phi_{r}\left(\left(x_{r-1}\right)^{*}\right) * \Phi_{r}\left(x_{r-1 f}\right)(g) .
\end{aligned}
$$


To see that $L^{1}(S)$ is symmetric we must show that $\left(-x^{*} x\right)$ is both right and left quasi-regular. For example, we must exhibit functions $y_{f} \in L^{1}(G)$ such that $y$ as defined above satisfies $y+x^{*} x y-x^{*} x=0$. We compute $x^{*} x y$.

$$
\begin{aligned}
x^{*} x y(f, g) & =I_{S}\left(x^{*} x[p, q] y\left[(p, q)^{-1}(f, g)\right]\right) \\
& \left.=I_{F}\left(I_{G}\left(\sum_{f \in F} \Phi_{r}\left(\left(x_{r-1}\right)^{*}\right) * \Phi_{r}\left(x_{r-1 p}\right)(q) \Phi_{p}\left(y_{p-1 f}\left(q^{-1} g\right)\right)\right)\right)\right) \\
& =\sum_{f \in F} \sum_{p \in F} \Phi_{r}\left(\left(x_{r-1}\right)^{*}\right) * \Phi_{r}\left(x_{r-1 p}\right) * \Phi_{p}\left(y_{p-1 f}\right)(g) .
\end{aligned}
$$

Let the group $F$ be written $F=\left\{f_{1}=e, f_{2}, \cdots, f_{n}\right\}$. Then the equations which must be satisfied are

$$
\begin{aligned}
y_{f_{i}}+ & \sum_{j=1}^{n} \sum_{k=1}^{n} \Phi_{r_{j}}\left(\left(x_{r_{j}^{-1}}\right)^{*}\right) * \Phi_{r_{j}}\left(x_{r_{j} p_{k}}^{-1}\right) * \Phi_{p_{k}}\left(y_{p_{k} f_{i}}\right) \\
& -\sum_{j=1}^{n} \Phi_{r_{j}}\left(\left(x_{r_{j}^{-1}}\right)^{*}\right) * \Phi_{r_{j}}\left(x_{r_{j}^{-1} f_{i}}\right)=0 . \quad i=1,2, \cdots, n .
\end{aligned}
$$

These are equivalent to

$$
\begin{aligned}
& y_{f_{i}}+\sum_{j=1}^{n} \sum_{m=1}^{n} \Phi_{r_{j}}\left(\left(x_{r_{j}^{-1}}\right)^{*}\right) * \Phi_{r_{j}}\left(x_{r_{j}^{-1} f_{i} q_{m}^{-1}}\right) * \Phi_{f_{i} q_{m}^{-1}}\left(y_{q_{m}}\right) \\
& -\sum_{j=1}^{n} \Phi_{r_{j}}\left(\left(x_{r_{j}}^{-1}\right)^{*}\right) * \Phi_{r_{j}}\left(x_{r_{j}^{-1} f_{i}}\right)=0 . \quad i=1,2, \cdots, n .
\end{aligned}
$$

Transforming both sides by $\Phi_{f_{i}^{-1}}$ we obtain the equations

$$
\begin{aligned}
\Phi_{f_{i}^{-1}}\left(y_{f_{i}}\right)+ & \sum_{j=1}^{n} \sum_{m=1}^{n} \Phi_{f_{i}^{-1} r_{j}}\left(\left(x_{r_{j}^{-1}}\right)^{*}\right) * \Phi_{f_{i}^{-1} r_{j}}\left(x_{r_{j}^{-1} f_{i} q_{m}^{-1}}\right) * \Phi_{q_{m}^{-1}}\left(y_{q_{m}}\right) \\
& -\sum_{j=1}^{n} \Phi_{f_{i}^{-1} r_{j}}\left(\left(x_{r_{j}^{-1}}\right)^{*}\right) * \Phi_{f_{i}^{-1} r_{j}}\left(x_{r_{j}}^{-1} f_{i}\right)=0, \quad i=1,2, \cdots, n .
\end{aligned}
$$

Finally,

$$
\begin{aligned}
\Phi_{f_{i}^{-1}}\left(y_{f_{i}}\right)+ & \sum_{k=1}^{n} \sum_{m=1}^{n} \Phi_{s_{k}}\left(\left(x_{s_{k}^{-1} f_{i}^{-1}}\right)^{*}\right) * \Phi_{s_{k}}\left(x_{s_{k}{ }^{-1} q_{m}}\right) * \Phi_{q_{m}}\left(y_{q_{m}^{-1}}\right) \\
& -\sum_{k=1}^{n} \Phi_{s_{k}}\left(\left(x_{s_{k}}^{-1} f_{i}^{-1}\right)^{*}\right) * \Phi_{s_{k}}\left(x_{s_{k}}^{-1}\right)=0, \quad i=1,2, \cdots, n .
\end{aligned}
$$

It is evidently enough to determine the functions $\Phi_{f_{i}^{-1}}\left(y_{f_{i}}\right)$, for from them the $y_{f_{i}}$ can be obtained on transforming by $\Phi_{f_{i}}$. Consider the matrix $A=\left[a_{i j}\right]$ of elements from $L^{1}(G)$ defined by

$$
a_{i j}=\Phi_{s_{i}}\left(x_{s_{i}}^{-1} f_{j}^{-1}\right), \quad i, j=1,2, \cdots, n .
$$

Since $L^{1}(G)$ is symmetric we know, by Theorem 1 , that $-A^{*} A$ has a quasiinverse, say $C=\left[c_{i j}\right]$ with $c_{i j} \in L^{1}(G)$. It follows from $C+A^{*} A C-A^{*} A=0$ that

$$
c_{i 1}+\sum_{k=1}^{n} \sum_{m=1}^{n} a_{k i}^{*} a_{k i} c_{m 1}-\sum_{k=1}^{n} a_{k i}^{*} a_{k 1}=0, \quad i=1,2, \cdots, n .
$$


Thus $\Phi_{q_{m}}\left(q_{m}^{-1}\right)=c_{m 1}, m=1,2, \cdots, n$ is a solution of the equations (2.2). A left quasi-inverse for $\left(-x^{*} x\right)$ can be computed in a similar manner. Hence $L^{1}(S)$ is symmetric.

\section{REFERENCES}

1. R. Bonic, Symmetry in group algebras of discrete groups, Pacific J. Math. 11 (1961), 73-94.

2. P. Civin and B. Yood, Involutions on Banach algebras, Pacific J. Math. 9 (1959), 415-436.

3. E. Hewitt and K. Ross, Abstract Harmonic Analysis, vol. I, Springer, 1963.

4. A. Hulanicki, On the spectral radius of hermitian elements in group algebras, Pacific J. Math. 18 (1966), 277-287.

5. C. Rickart, General Theory of Banach Algebras, D. Van Nostrand, 1960.

Received May, 20, 1964, and in revised form April 5, 1967.

AmHerst College

AmHerst, Massachusetts 



\section{PACIFIC JOURNAL OF MATHEMATICS}

\section{EDITORS}

\author{
H. ROYDEN \\ Stanford University \\ Stanford, California
}

\author{
J. P. JANS \\ University of Washington \\ Seattle, Washington 98105
}

J. DugundJI

Department of Mathematics

Rice University

Houston, Texas 77001

RICHARD ARENS

University of California

Los Angeles, California 90024

\section{ASSOCIATE EDITORS}
E. F. BECKENBACH
B. H. NeumanN
F. WOLF
K. YOSIDA

\section{SUPPORTING INSTITUTIONS}

\author{
UNIVERSITY OF BRITISH COLUMBIA \\ CALIFORNIA INSTITUTE OF TECHNOLOGY \\ UNIVERSITY OF CALIFORNIA \\ MONTANA STATE UNIVERSITY \\ UNIVERSITY OF NEVADA \\ NEW MEXICO STATE UNIVERSITY \\ OREGON STATE UNIVERSITY \\ UNIVERSITY OF OREGON \\ OSAKA UNIVERSITY \\ UNIVERSITY OF SOUTHERN CALIFORNIA
}

\author{
STANFORD UNIVERSITY \\ UNIVERSITY OF TOKYO \\ UNIVERSITY OF UTAH \\ WASHINGTON STATE UNIVERSITY \\ UNIVERSITY OF WASHINGTON \\ AMERICAN MATHEMATICAL SOCIETY \\ CHEVRON RESEARCH CORPORATION \\ TRW SYSTEMS \\ NAVAL ORDNANCE TEST STATION
}

\footnotetext{
Mathematical papers intended for publication in the Pacific Journal of Mathematics should be in typed form or offset-reproduced, double spaced with large margins. Underline Greek letters in red, German in green, and script in blue. The first paragraph or two must be capable of being used separately as a synopsis of the entire paper. It should not contain references to the bibliography. Manuscripts may be sent to any one of the four editors. All other communications to the editors should be addressed to the managing editor, Richard Arens, University of California, Los Angeles, California 90024.

Each author of each article receives 50 reprints free of charge; additional copies may be obtained at cost in multiples of 50 .

The Pacific Journal of Mathematics is published monthly. Effective with Volume 16 the price per volume (3 numbers) is $\$ 8.00$; single issues, $\$ 3.00$. Special price for current issues to individual faculty members of supporting institutions and to individual members of the American Mathematical Society: $\$ 4.00$ per volume; single issues $\$ 1.50$. Back numbers are available.

Subscriptions, orders for back numbers, and changes of address should be sent to Pacific Journal of Mathematics, 103 Highland Boulevard, Berkeley 8, California.

Printed at Kokusai Bunken Insatsusha (International Academic Printing Co., Ltd.), 7-17, Fujimi 2-chome, Chiyoda-ku, Tokyo, Japan.

PUBLISHED BY PACIFIC JOURNAL OF MATHEMATICS, A NON-PROFIT CORPORATION

The Supporting Institutions listed above contribute to the cost of publication of this Journal, but they are not owners of publishers and have no responsibility for its content or policies.
} 


\section{Pacific Journal of Mathematics}

\section{Vol. 24, No. $3 \quad$ July, 1968}

Duane W. Bailey, On symmetry in certain group algebras ............ 413

Lawrence Peter Belluce and Surender Kumar Jain, Prime rings with a one-sided ideal satisfying a polynomial identity ................ 421

L. Carlitz, A note on certain biorthogonal polynomials ............. 425

Charles O. Christenson and Richard Paul Osborne, Pointlike subsets of a manifold ......................................... 431

Russell James Egbert, Products and quotients of probabilistic metric

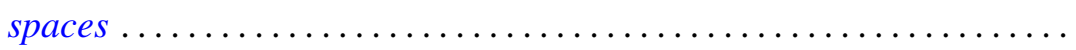

Moses Glasner, Richard Emanuel Katz and Mitsuru Nakai, Bisection into small annuli ..................................... 457

Karl Edwin Gustafson, A note on left multiplication of semigroup

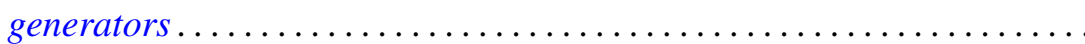

I. Martin (Irving) Isaacs and Donald Steven Passman, A characterization of groups in terms of the degrees of their characters. II ............. 467

Howard Wilson Lambert and Richard Benjamin Sher, Point-like

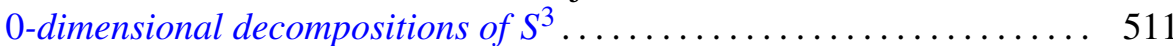

Oscar Tivis Nelson, Subdirect decompositions of lattices of width two ..... 519

Ralph Tyrrell Rockafellar, Integrals which are convex functionals . . . . . . . 525

James McLean Sloss, Reflection laws of systems of second order elliptic differential equations in two independent variables with constant coefficients ...

Bui An Ton, Nonlinear elliptic convolution equations of Wiener-Hopf type in a bounded region

Daniel Eliot Wulbert, Some complemented function spaces in $C(X)$

Zvi Ziegler, On the characterization of measures of the cone dual to a generalized convexity cone. 